\title{
An Investigation on the Effect of Solvent and Heat to Clay Minerals in Shaly Sandstone
}

\author{
Wan Zairani Wan Bakar ${ }^{1,2, *}$, Ismail Mohd Saaid ${ }^{2}$, Mohd Riduan Ahmad ${ }^{3}$, \\ Husna Hayati Jarni ${ }^{1}$, and Siti Qurratu' Aini Mahat ${ }^{2}$ \\ ${ }^{1}$ Oil and Gas Department, Faculty of Chemical Engineering, Universiti Teknologi MARA, 40450 Shah Alam, Selangor, Malaysia \\ ${ }^{2}$ Department of Petroleum Engineering, Universiti Teknologi PETRONAS, 32610 Seri Iskandar, Perak, Malaysia \\ ${ }^{3}$ Onyx Engineering Sdn Bhd, Jl. Perusahaan 4, 68100 Batu Caves, Selangor, Malaysia
}

* Corresponding author:

tel: $+60-192636695$

email:zairani@uitm.edu.my

Received: July 23, 2019

Accepted: December 30, 2019

DOI: $10.22146 / \mathrm{ijc} .48010$

\begin{abstract}
Core cleaning could be complicated for samples that contain a high amount of clays. Some clays are delicate and exposure to solvent and heat would damage or alter its properties. In this study, we investigated the effect of direct exposure of solvent and heat to clay mineral properties based on petrographical data from X-Ray Diffraction (XRD), Fourier Transform Infrared Spectroscopy (FTIR), Field Emission Scanning Electron Microscope (FESEM) and Energy Dispersive X-Ray (EDX). Experiments were performed on sidewall core samples taken in a shaly sand zone. The FTIR data did not show any changes at the molecular level to the clay mineral after direct contact with the selected solvent. The FESEM images showed some illite floccules collapse in the samples exposed to oven-drying at $60^{\circ} \mathrm{C}$.
\end{abstract}

Keywords: clay minerals; core cleaning; petrography; solvent; heat exposure

\section{- INTRODUCTION}

Core analysis data is an important source of information for understanding formation characteristics as well as for calibrating with down hole well log data. Therefore, the information should be obtained from core samples that are representative of their native states and free from contaminants. Drilling mud and its additives are well-known sources of contamination that occur during drilling. It may alter rock surface chemistry and consequently affected important rock properties. These contaminants must be removed prior to any other measurement. However, the removal of these contaminants could be complicated especially from tight and delicate samples. Unsuitable techniques and solvent used in the cleaning process might lead to undesirable measurements as a result of the alteration of native rock properties. It has been reported that properties such as porosity, permeability and wettability are highly affected by the technique and solvent used in cleaning [1-4]. For samples with high clay content, the usage of solvent and exposure to heat might alter the electrochemical properties of the minerals.
Clay minerals are phyllosilicates with the tetrahedral layer and octahedral layer as the basic building block. The tetrahedral layer consists of either $\mathrm{Si}$ or Al bonding with the basal oxygen in tetrahedral coordination while the octahedral layer consists of cations ( $\mathrm{Si}, \mathrm{Al}$ or $\mathrm{Mg}$ ) bonding with the basal oxygen in octahedral coordination. The structure of the clay determines its physical, electrochemical, rheological and thermal properties [5-6]. The alumino-silicates minerals appear as layering either in 2:1 or 1:1 ratio. In 1:1 clay minerals, the repetition of tetrahedron-octahedron ( $\mathrm{T}-$ O) sheets in one layer disallows for alkali metal cations or water molecules to exist between them. In 2:1 structure the repetition of tetrahedron-octahedrontetrahedron ( $\mathrm{T}-\mathrm{O}-\mathrm{T})$ sheets in one layer provides space for cations occupancy [7]. Smectite and illite are examples of 2:1 phyllosilicate (2 tetrahedral and 1 octahedral layer) and kaolinite is a 1:1 phyllosilicate. The 2:1 clay minerals only contain siloxane surfaces while the 1:1 clay minerals contain both the siloxane and hydroxyl surfaces [8]. The siloxane surface allows isomorphous substitutions by cations of lower valance at octahedral 
sites, leaving the surface with positive charge deficiency. The charge deficiency is balanced by hydrated interlayer cations, which are easily released in water and exchanged with other cations, which contributes to electrical conductivity. Water can be bonded to the exchangeable cations or directly to the clay mineral surface.

Soxhlet extraction is one of the normal procedures used in core cleaning. In the Soxhlet procedure heat is introduced to vaporize the solvent, which also exposed the samples to heat. The samples were exposed to another heat by oven drying to remove pore water after cleaning. Nevertheless, earlier studies have been reported that exposure to heat during cleaning and drying would have impacted the rock properties. Bush and Jenkins [9] reported increasing errors in dry porosity and permeability for decreasing the values of the parameters. This was due to the removal of adsorbed water on the clay surface when exposed to heat in a Soxhlet procedure. From the study, it was suggested that at least one to two layers of adsorbed water on the clay surfaces should be retained when measuring the permeability and porosity of cores. Soeder et al. [4] claimed that unhumidified drying could cause a significant increase in permeability as a result of hydration water removal and the collapse of clay minerals.

A study by Pallatt et al. [10] exhibited that dehydration and shrinkage of clay minerals due to oven-dried had produced much higher permeability as compared to the wet and preserved state. Since clay minerals is a material that originally has a hydrophilic character due to the presence of the surface hydroxyl $(-\mathrm{OH})$ groups that link easily to water molecules, hydration due to heat might affect the bonding to water molecules. This will consequently affect its electrical properties, which is related to the electrical current flow through hydrated clay surfaces. As an alternative, solvent flush cleaning without vapor is recommended for samples with delicate clays but this method incurs high cost and Soxhlet is preferable.

The use of solvent and heat in core cleaning is common to effectively remove mud contamination and pore fluid prior to the measurement of other rock properties. The possible effect of solvent to rock properties is balanced with the need to remove the contaminants in order to bring back the rock sample to its native state. Other than the effect of heat discussed earlier on, other studies also reported the effect of some organic solvent of varying polarities and dielectric to clay structure at a molecular level [11]. In this study, we analyzed any changes that might occur to the clay mineral structure as a result of the cleaning process. The mineral was analyzed X-Ray Diffraction (XRD), Fourier Transform Infra-Red (FTIR), Field Emission Scanning Electron Microscope (FESEM) and Energy Dispersive X-Ray (EDX).

\section{- EXPERIMENTAL SECTION}

\section{Materials}

Laboratory analysis was performed on fresh samples taken in the Malay Basin where high compaction was expected. The sample was cored in the shaly sand zone on top of a gas reservoir and was preserved at low temperatures from the well site to protect from heat and keep the moisture. Gamma Ray from good log shows high reading indicating high shale content. As synthetic oil based mud was used during drilling, high resistivity reading at the near borehole wall as shown by induction log data indicates high mud contamination. The sample was carefully handled and preserved from the well site. Therefore, it was expected that any changes that would be observed after cleaning is due to response to the solvent and heat; and not from the surrounding effects.

\section{Procedure}

\section{XRD}

Relative mineral content was analyzed using the Empyrean XRD equipment. The mineralogical analysis using XRD was performed in a few steps involving bulk clays, glycolation, and heating at 350 and $550{ }^{\circ} \mathrm{C}$. For first evaluation of the relative amount of bulk clays, a powdered sample was scanned over a $2 \theta$ range of $2-70^{\circ}$ with $\mathrm{CuKa}$ radiation (1.5406) at a scan step time 148.92 and step width of $0.0260^{\circ}$. The generator was set at 40 $\mathrm{mA}$ and $45 \mathrm{kV}$. The proportion of clay minerals in the sample was further analyzed at clay size $<2 \mu \mathrm{m}$. $1.5 \mathrm{~g}$ of the powdered sample was mixed with 3 drops of calgon 
in a small tube to further break down the sample particles. Thirty milliliter distilled water was added and the mixture was well shaken before entering the ultrasonic bath for $10 \mathrm{~min}$. Sample slurry was left for $24 \mathrm{~h}$ before air-dried on glass slides. The sample was then scanned using the same configuration as for bulk measurement. Ethylene glycol was used to detect the swelling components and estimate the illite-smectite composition. Sample on the glass slide was put side by side with ethylene glycol in a container and put in the oven at $80^{\circ} \mathrm{C}$ for 30 min before scanned again. The sample was heated to 350 and $550{ }^{\circ} \mathrm{C}$ for $30 \mathrm{~min}$ before scanned again to distinguish kaolinite from chlorite.

\section{FTIR, FESEM, and EDX}

Two types of FTIR equipment were used to analyze the mineral content and structural change. The quantitative analysis was performed using bench top FTIR while Perkin Elmer FTIR Spectrometer was used to generate the spectrum in the range between 400 to 4000 $\mathrm{cm}^{-1}$. Both types of equipment used the attenuated total reflection (ATR) method. The mid-range of infrared frequency was chosen as many minerals exhibit vibration modes within this range. For sample preparation, four offcuts from the sample were cleaned with four different types of solvent; methanol, toluene, chloroform and azeotrope (70\% chloroform and 30\% methanol). The effluent was checked every day until no further changes in the color were observed. The effluent was analyzed using Gas chromatography-mass spectrometry (GCMS) to study the component of contaminants being removed. Three types of drying were used for the samples cleaned with toluene; ambient, $60{ }^{\circ} \mathrm{C}$ with $40 \%$ humidity and $60{ }^{\circ} \mathrm{C}$ oven dry. Samples were ground to fine powder form prior to FTIR analysis. The powdered samples were also analyzed using Quanta FEG 450 FESEM and EDX.

\section{- RESULTS AND DISCUSSION}

\section{XRD Analysis}

XRD data indicates the mineral constituents of the sample are consist of illite, kaolinite, chlorite, and quartz (Fig. 1). Characteristic reflection related to $10 \AA$ periodicity that remains unchanged after ethylene glycol treatment indicates the presence of illite. Further confirmation is achieved with unchanged reflection after 350 and $550^{\circ} \mathrm{C}$ treatment. Kaolinite and chlorite were identified from the reflection related to $7 \AA$ that remains unchanged following ethylene glycol treatment. There are no changes in the reflection after $550{ }^{\circ} \mathrm{C}$ ignition indicates the presence of kaolinite rather than chlorite. Residual reflection identified at $7 \AA$ is corresponding to kaolinite whereas chlorite would be destroyed at $450{ }^{\circ} \mathrm{C}$ heat [7]. However, the unchanged reflection after $550{ }^{\circ} \mathrm{C}$ heating could also indicate the existence of antigorite together with kaolinite. The presence of chlorite is indicated by the

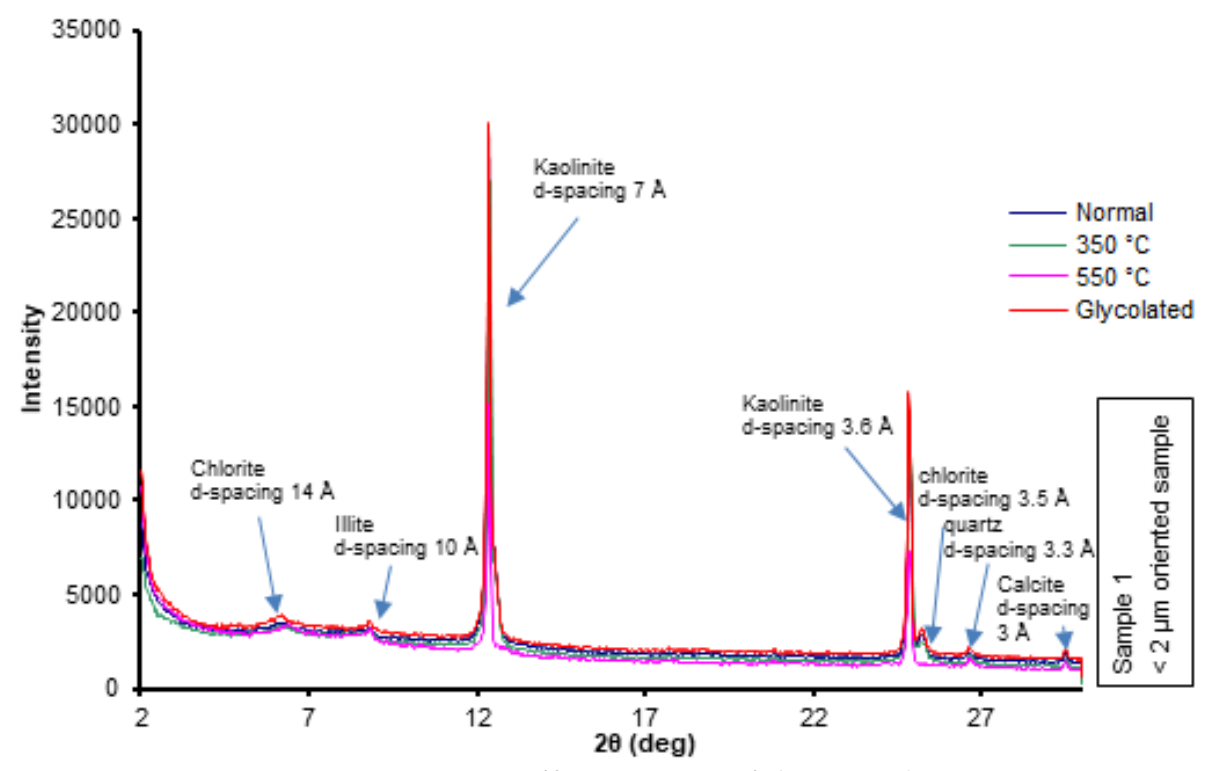

Fig 1. X-Ray Diffractogram of the sample 
reflection at $14 \AA$ periodicity that is unaltered following glycolation. The reflection slightly collapsed after $550{ }^{\circ} \mathrm{C}$ heating shows the presence of vermiculite alongside with the other minerals. Quartz was identified based on reflection related to $3 \AA$ periodicity in the data.

\section{EDX}

The quantitative EDX analysis (Table 1) suggested $O$ and $\mathrm{Si}$ as dominant elements in the sample. These elements are common in both quartz and clay minerals. $\mathrm{Al}$ and $\mathrm{K}$, which are common in illite and kaolinite are found in smaller quantities. Fe also found in small quantities, which confirms the presence of illite as indicated by XRD and FTIR data. Minor concentrations of $\mathrm{Na}$ and $\mathrm{Mg}$ were also found in the sample. $\mathrm{Mg}$ is common is illite but $\mathrm{Na}$ is usually found in smectite. Since the XRD data did not indicate the presence of smectite, $\mathrm{Na}$ found in the EDX data could be attributed to residual impurities.

\section{FTIR}

Using the benchtop FTIR the mineral spectrum of the samples was automatically compared to a spectral library stored in the equipment. The mineral content in the samples was produced as a percentage as in Fig. 2 . Consistent with the XRD result, FTIR data also recorded the presence of quartz, illite, kaolinite and chlorite. For the purpose of analysis, $10 \%$ tolerance is accepted for comparison of mineral content in each sample. Samples from toluene and chloroform recorded the same amount of quartz, illite, kaolinite and chlorite (within the acceptable tolerance). Samples from methanol and azeotrope recorded more quartz and less illite. Kaolinite and chlorite also presence in a smaller amount. The difference could be due to inefficient cleaning by methanol as inferred by the effluent's color. It had been observed that the effluent from samples in methanol was clear while effluent from toluene and chloroform were blackish. Effluent from azeotrope showed lighter color as compared to toluene and chloroform. This indicates that toluene and chloroform provide efficient cleaning while methanol is not suitable for this type of mud. This is supported by a study by Gupta et al. [2], who reported that toluene and chloroform have similar cleaning efficiencies. On the other hand, methanol is more suitable for removing polar components and dissipated salt [1]. The presence of mud contamination could have concealed the actual spectrum. The GCMS result indicates an abundance of alkane hydrocarbon (tridecane, undecane, ethyl, cyclopentane) and acid (oxalic and sulfuric) and no traces of components from

Table1. EDX result

\begin{tabular}{cccc}
\hline No & Element & Weight \% & Atomic \% \\
\hline 1 & $\mathrm{O}$ & $56.53 \pm 1.54$ & 70.52 \\
2 & $\mathrm{Na}$ & $0.24 \pm 0.12$ & 0.21 \\
3 & $\mathrm{Mg}$ & $0.29 \pm 0.12$ & 0.24 \\
4 & $\mathrm{Al}$ & $5.44 \pm 0.25$ & 4.02 \\
5 & $\mathrm{Si}$ & $32.52 \pm 0.95$ & 23.11 \\
6 & $\mathrm{~K}$ & $1.39 \pm 0.17$ & 0.71 \\
7 & $\mathrm{Ca}$ & $0.36 \pm 0.14$ & 0.18 \\
8 & $\mathrm{Ti}$ & $0.27 \pm 0.16$ & 0.11 \\
9 & $\mathrm{Fe}$ & $2.37 \pm 0.38$ & 0.85 \\
10 & $\mathrm{U}$ & $0.58 \pm 0.5$ & 0.05 \\
\hline \multicolumn{5}{c}{$\mathrm{Total}$} & 100 & 100 \\
\hline
\end{tabular}

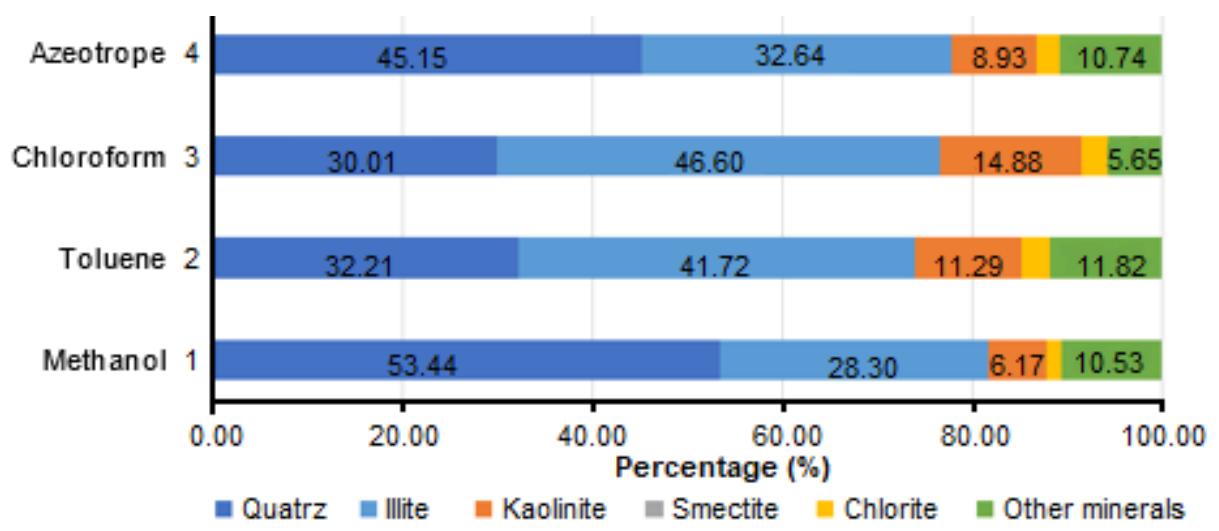

Fig 2. FTIR analysis result on percentage of clay minerals 


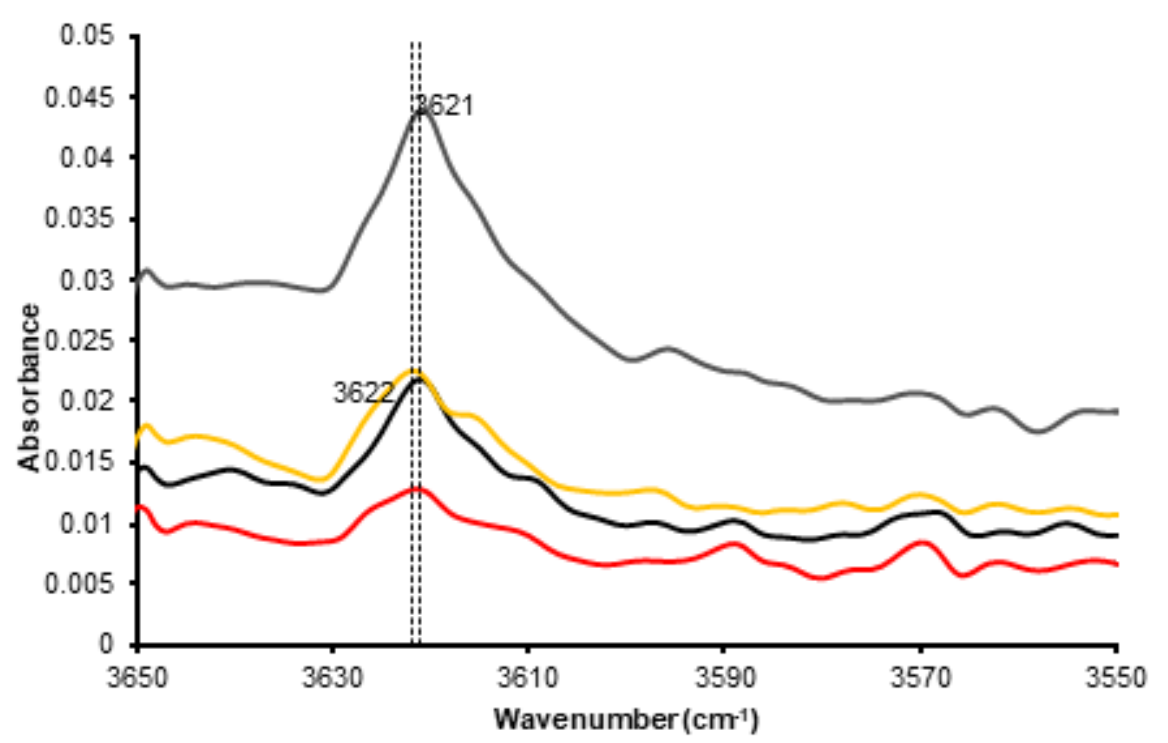

Fig 3. From top to bottom; FTIR spectrum for samples cleaned with chloroform, azeotrope, toluene, and methanol for 3600 to $3500 \mathrm{~cm}^{-1}$

quartz minerals $(\mathrm{O}, \mathrm{Si})$. This excluded the possibility that quartz has been removed by toluene and chloroform.

The FTIR spectrum of the samples was further analyzed to study any changes to the mineral structure. FTIR spectrum for all samples shows absorbance in the $1200-400 \mathrm{~cm}^{-1}$ region and vibration at near $3620 \mathrm{~cm}^{-1}$ (Fig. 3 and 4). The $3620 \mathrm{~cm}^{-1}$ bands are corresponding to the stretching vibration of an inner hydroxyl group, lying between the tetrahedral and octahedral sheets [12]. The band is found in pure kaolinite and also in smectite that has a high amount of $\mathrm{Al}$ in the octahedral [12-13]. We believed that this energy bend represents kaolinite since smectite was unidentified by XRD analysis. The hydroxyl groups in kaolinite are bonded to octahedral cations, but residing largely within the plane of apical oxygen atoms that link the tetrahedral and octahedral sheets. The stretching region of samples cleaned with toluene, chloroform and azeotrope had shifted to higher energy band by $1 \mathrm{~cm}$ while the samples cleaned with methanol had shifted to higher energy band by $2 \mathrm{~cm}$ from the common band of pure kaolinite. Methanol is an intermediate polarity organic solvent, which has the ability to interact with clay surface oxygen and structural hydroxyl groups while toluene and chloroform are nonpolar molecules that have a low influence on clay structure. Some other solvent with a very high polarity such as formamide had shown very strong nonbonding interaction with $\mathrm{Na}$-montmorillonite structure that consequently affect its hydraulic conductivity [11]. However, very low energy shifting indicated that the hydroxyl stretching is able to return to its original energy band. The shifting to $3622 \mathrm{~cm}^{-1}$ in methanol exhibits an energy band as in dickite. Dickite is a 1:1 phyllosilicate that has identical chemical composition and structure of the individual layer to kaolinite but differs in the layer stacking arrangement. Kaolinite has a single-layer structure instead of double-layer polytype.

The energy band between $1200-400 \mathrm{~cm}^{-1}$ in the samples are corresponding to stretching and bending of Si-O and bending of $\mathrm{OH}$ from several minerals. The vibrations at 1116, 1029, 996, 935 and $908 \mathrm{~cm}^{-1}$ are closed to kaolinite with shifting to lower energy within 3 to $15 \mathrm{~cm}$. These vibrations are attributes to $\mathrm{Si}-\mathrm{O}$ stretching. The $908 \mathrm{~cm}^{-1}$ energy band is closed to the inner surface $\mathrm{OH}$ groups bending region of kaolinite at $913 \mathrm{~cm}^{-1}$. All samples exhibited the same vibrations pattern that shows all solvent had a similar influence on the clay structure of the sample. $1029 \mathrm{~cm}^{-1}$ energy band is close to Si-O stretching vibrations in illite at $1030 \mathrm{~cm}^{-1}$ and muscovite at $1028 \mathrm{~cm}^{-1}$. The lower energy bands at 522 , 463 and $422 \mathrm{~cm}^{-1}$ carry almost similar patterns to those found in illite. No shifting in energy has been observed from all the samples. 


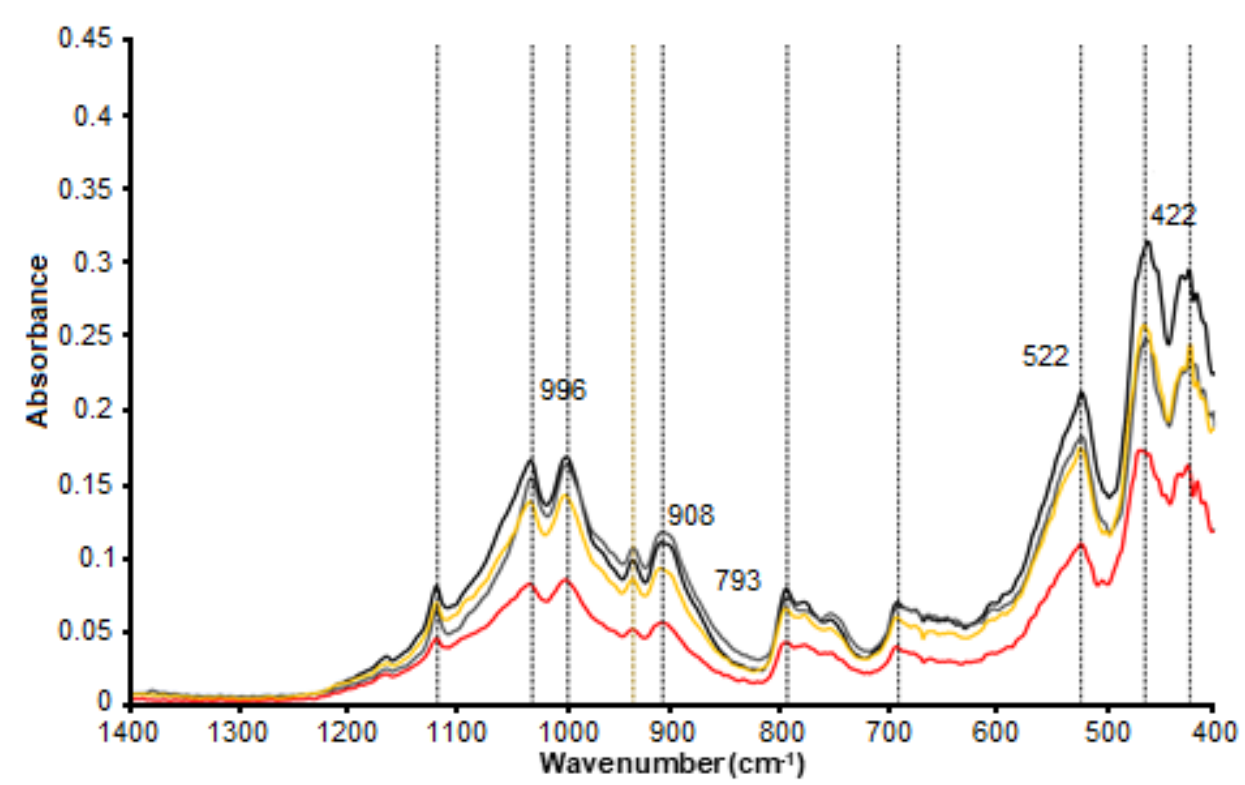

Fig 4. From top to bottom; FTIR for samples cleaned with toluene, chloroform, azeotrope and methanol for 1200 to $400 \mathrm{~cm}^{-1}$

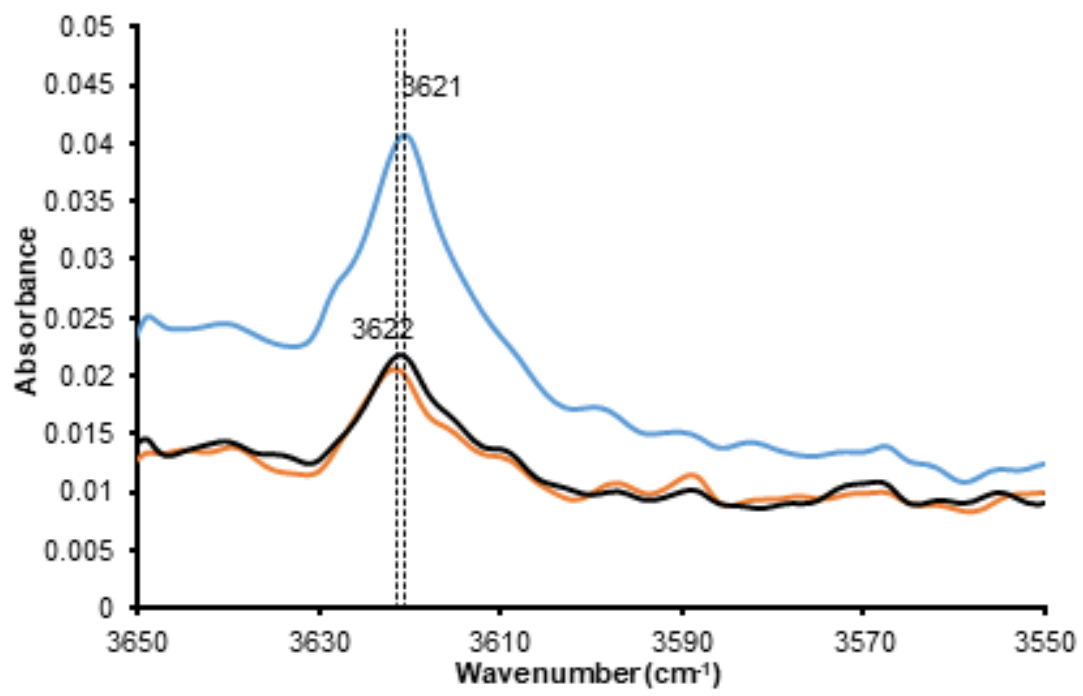

Fig 5. From top to bottom; the FTIR spectrum for samples dried at ambient, $60^{\circ} \mathrm{C}$ humidity and $60{ }^{\circ} \mathrm{C}$ oven-dried for 3600 to $3500 \mathrm{~cm}^{-1}$

The FTIR data for samples dried at ambient, $60^{\circ} \mathrm{C}$ humidity and $60^{\circ} \mathrm{C}$ oven-dried also shows a slight effect on the clay structure based on energy shifting in Fig. 5 and 6. All samples exhibited the same pattern with insignificant shifting in the energy band between 1200 to $400 \mathrm{~cm}^{-1}$.

\section{FESEM}

FESEM images indicate that the clay minerals in the sample are dominated by kaolinite and illite (Fig. 7). The ragged appearance of the flat platelets exhibited that the illite is detrital in origin [14]. These two types of clay minerals are common in the Malay Basin. Illite flocculation of typical edge-face cardhouse orientation has been observed in the sample after toluene cleaning and dried at ambient temperature (Fig. 8). Flocculation happens when clumps of electrostatically charged clay flakes sink in ion-enriched salty water and form a "cardhouse" structure of individual edge-face or edgeedge-oriented flakes and/or domains of face-faceoriented flakes. This may generate pores, which when 


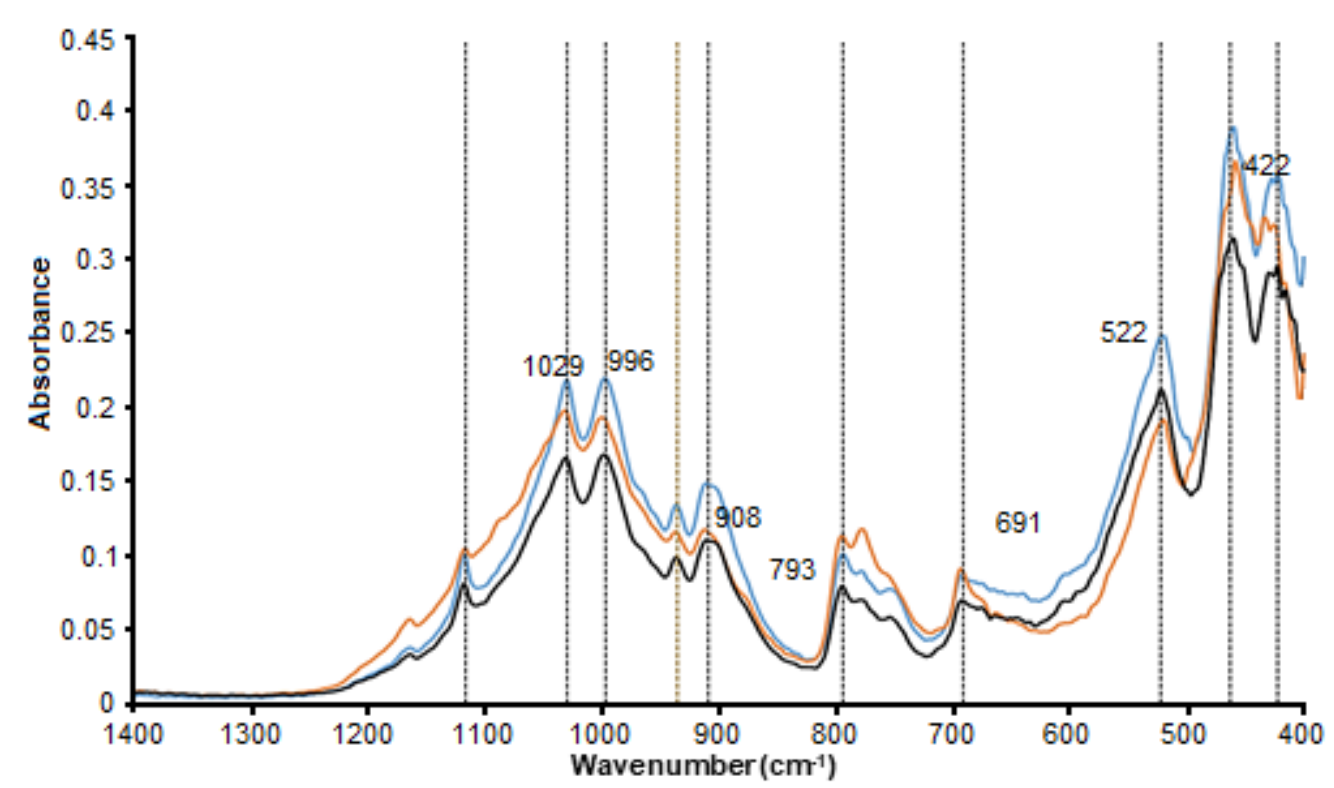

Fig 6. From top to bottom; the FTIR spectrum for samples dried at ambient, $60^{\circ} \mathrm{C}$ humidity and $60{ }^{\circ} \mathrm{C}$ oven-dried for 1200 to $400 \mathrm{~cm}^{-1}$

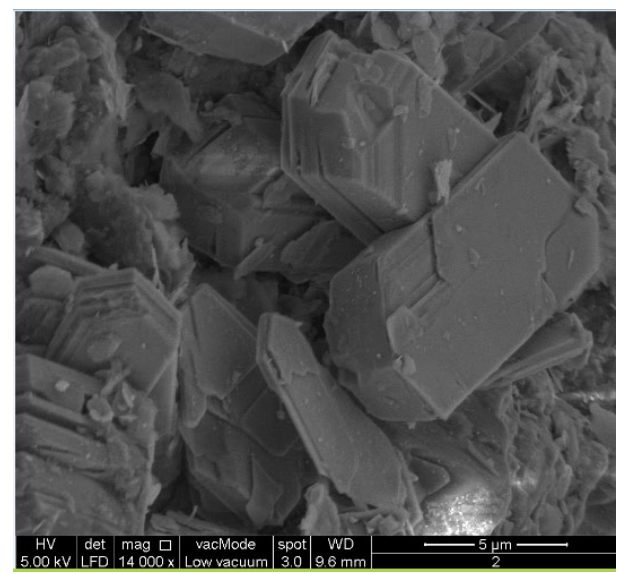

Fig 7. Kaolinite surrounded by illite

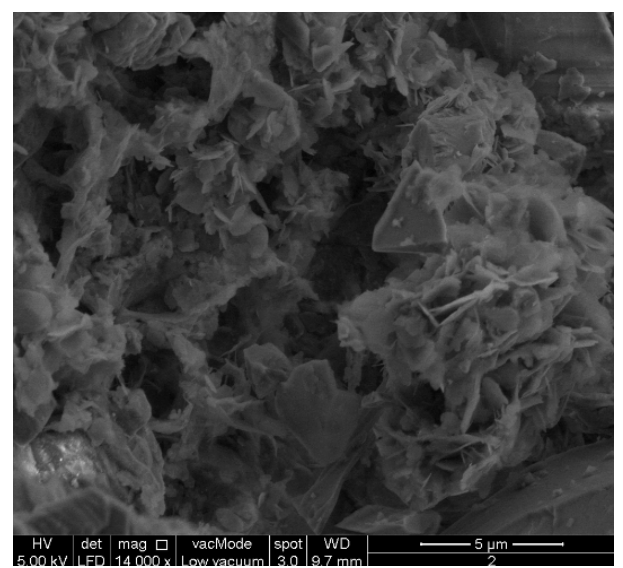

Fig 8. FESEM image of illite flocculation for sample dried at ambient temperature

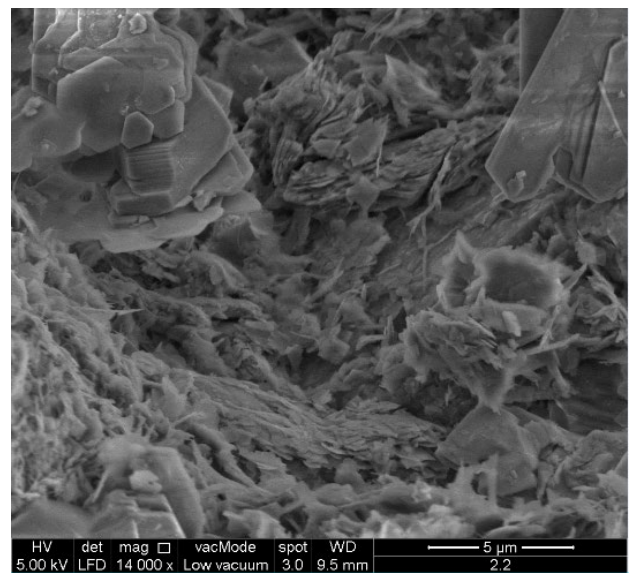

Fig 9. FESEM image of the sample after oven-dried at $60^{\circ} \mathrm{C}$

interconnected will form permeability pathways. The edge-face and face-face flocculation is common in clay aggregates and happens in the presence of either fresh or salt water [15]. The illite floccules and kaolinite structures show that the mineral survived and less affected by toluene cleaning.

Floccules collapsed (Fig. 9) has been observed in the sample after $60{ }^{\circ} \mathrm{C}$ oven-dried. The collapse of the floccules structure might be due to dehydration upon oven-heating. A similar effect in a different type of illite clays had been observed in an earlier study by Pallatt et al. [10]. The SEM photograph of filamentous diagenetic 
illite clays in the report showed that the open mesh was compacted against pore walls due to oven-drying. This had created a larger path for fluid to flow and increased permeability.

\section{GCMS}

The Gas chromatography-mass spectrometry
(GCMS) result of effluent from methanol, toluene or chloroform cleaning shows no traces of clay mineral components being removed or dissolved in the solvents (Fig. 10(a) to (b)). The effluent from toluene shows a high amount of hydrocarbon component and acid, which is expected from the drilling mud contamination. This shows that toluene interacts well with hydrocarbon
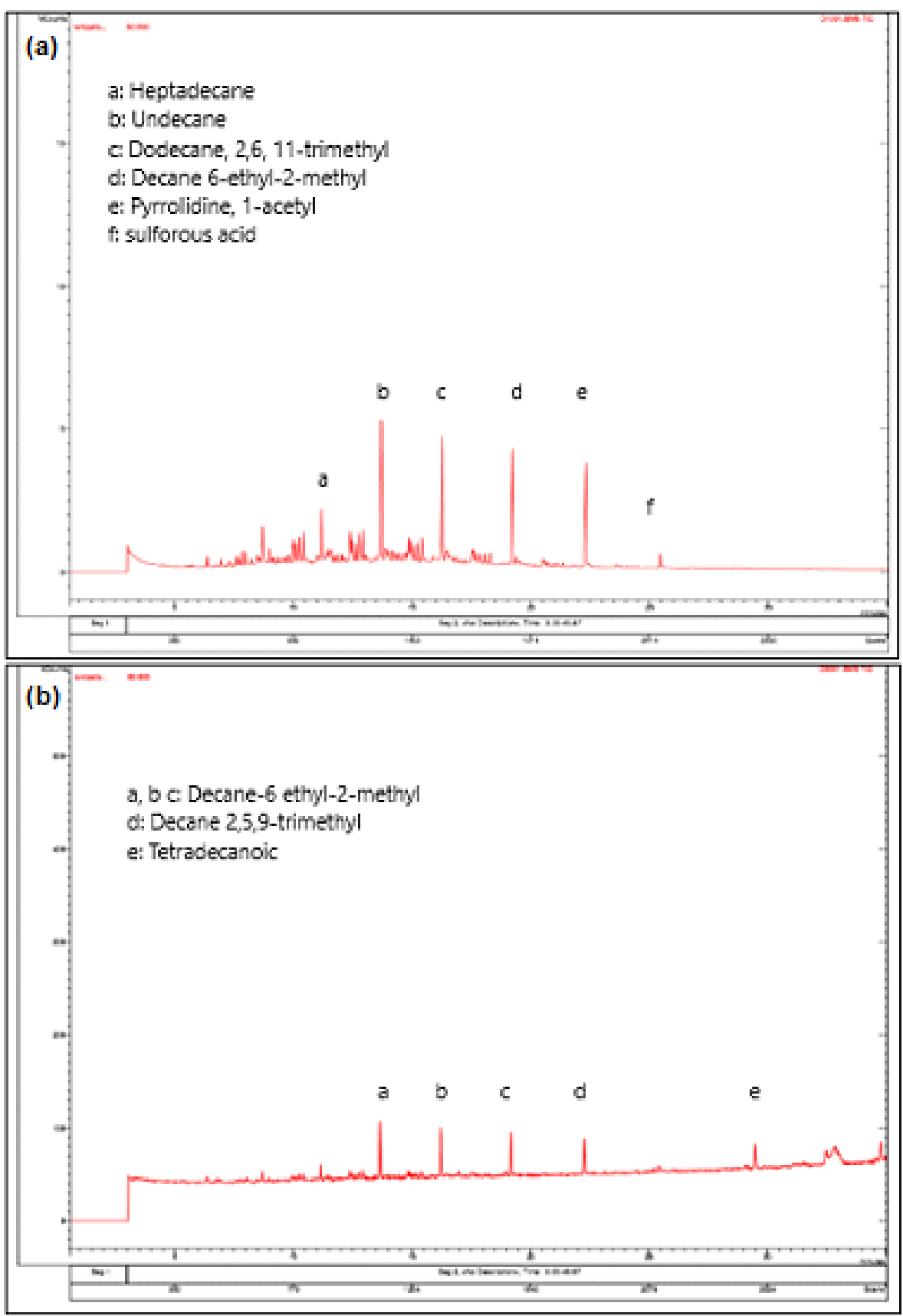

Fig 10. (a) chromatogram for effluent from toluene cleaning and (b) chromatogram for effluent from methanol cleaning 
in drilling mud but does not give any effect to the clay mineral. A lesser amount of hydrocarbon component was recorded in the effluent from methanol cleaning showing that methanol alone is less efficient to remove the contaminants but better interaction with water and salt. We did not manage to get the result for effluent from chloroform cleaning due to evaporation prior to the test.

\section{- CONCLUSION}

The FTIR result showed that direct contact with the selected solvent does not give any impact at the molecular level to the clay minerals in the sample. Toluene and chloroform are very-low polarity solvents that do not have a strong ability to interact with water or negatively charged clay sheets but only with the hydrocarbon component from the synthetic based mud. Methanol is an intermediate polarity solvent that can interact with water and oxygen on the clay surface but the kaolinite, illite and chlorite constituted in the sample are a type of nonexpandable clay minerals, which have a tight crystal structure and low bonding with water. Kaolinite and illite have been reported to release the physically bound water at temperatures 55 and $72{ }^{\circ} \mathrm{C}$ respectively [16] but the effect had not been observed from FTIR data in this study.

The illite floccules collapse from the FESEM images could possibly due to the heat exposure during ovendrying. This could lead to enlargement of the fluid flow path and consequently increase porosity and permeability. The impact of these two parameters was not investigated here but should be further studied alongside with the impact of other parameters such as wettability and electrical properties.

\section{- ACKNOWLEDGMENTS}

This research is supported by YUTP 0153AA-H05 and FRGS 5/3 (322/2019). The author also acknowledges the sponsorship of the program from the Ministry of Higher Education (MOHE), Malaysia (SLAI Fellowship Scheme), together with Universiti Teknologi MARA (UiTM), Malaysia. The author would also like to thank Onyx Engineering Sdn Bhd for their technical support.

\section{- REFERENCES}

[1] Gant, P.L., and Anderson, W.G., 1988, Core cleaning for the restoration of native wettability, SPE Form. Eval., 3 (1), 131-138.

[2] Gupta, I., Rai, C., Tinni, A., and Sondergeld, C., 2017, Impact of different cleaning methods on petrophysical measurements, Petrophysics, 58 (6), 613-621.

[3] Jennings, H.Y., 1957, Effect of Laboratory Core Cleaning on Water-Oil Relative Permeability, Fall Meeting of the Society of Petroleum Engineers of AIME, 6-9 October 1957, Dallas, Texas, SPE-897-G.

[4] Soeder, D.J., 1986, Laboratory drying procedures and the permeability of tight sandstone core, SPE Form. Eval., 1 (1), 16-22.

[5] Cho, D.W., Chon, C.M., Kim, Y., Jeon, B.H., Schwartz, F.W., Lee, E.S., and Song, H., 2011, Adsorption of nitrate and $\mathrm{Cr}(\mathrm{VI})$ by cationic polymer-modified granular activated carbon, Chem. Eng. J., 175, 298-305.

[6] Kloprogge, J.T, 1998, Synthesis of smectites and porous pillared clay catalysts: A review, J. Porous Mater., 5 (1), 5-41.

[7] Grim, R.E., and Joitns, W.D., 1954 Clay mineral investigation of sediments in the northern Gulf of Mexico, Clays Clay Miner., 2, 81-103.

[8] Djomgoue, P., and Njopwouo, D., 2013, FT-IR spectroscopy applied for surface clays characterization, J. Surf. Eng. Mater. Adv. Technol., 3 (4), 275-282.

[9] Bush, D.C., and Jenkins, R.E., 1970, Proper hydration of clays for rock property determinations, J. Pet. Technol., 22 (7), 800-804.

[10] Pallatt, N., Wilson, J., and McHardy, B., 1984, The relationship between permeability and the morphology of diagenetic illite in reservoir rocks, $J$. Pet. Technol., 36 (12), 2-225.

[11] Amarasinghe, P.M., Katti, K.S., and Katti, D.R., 2009, Nature of organic fluid-montmorillonite interactions: An FTIR spectroscopic study, J. Colloid Interface Sci., 337 (1), 97-105.

[12] Madejová, J., 2003, FTIR techniques in clay mineral studies, Vib. Spectrosc., 31 (1), 1-10.

[13] Vaculíková, L., and Plevová, E., 2005, Identification of clay minerals and micas in sedimentary rocks, 
Acta Geodyn. Geomater., 2 (2), 167-175.

[14] Huggett, J.M., 1995, Formation of authigenic illite in palaeocene mudrocks from the central North Sea: A study by high resolution electron microscopy, Clays Clay Miner., 43 (6), 682-692.

[15] O'Brien, N.R., 1971, Fabric of kaolinite and illite floccules, Clays Clay Miner., 19 (6), 353-359

[16] Kubliha, M., Trnovcová, V., Ondruška, J., Štubňa, I., Bošák, O., and Kaljuvee, T., 2017, Comparison of dehydration in kaolin and illite using DC conductivity measurements, Appl. Clay Sci., 149, 812.

[17] Madejová, J., and Komadel, P., 2001, Baseline studies of the clay minerals society source clays: Infrared methods, Clays Clay Miner., 49 (5), 410-432.

[18] Pironon, J., Pelletier, M., De Donato, P., and Mosser-Ruck, R., 2003, Characterization of smectite and illite by FTIR spectroscopy of interlayer $\mathrm{NH}_{4}^{+}$cations, Clay Miner., 38 (2), 201211. 